\title{
Effect of Intradiscal Methylene Blue Injection for the Chronic Discogenic Low Back Pain: One Year Prospective Follow-up Study
}

\author{
Soo-Hyun Kim, M.D., Sang-Ho Ahn, M.D., Ph.D., Yun-Woo Cho, M.D., Ph.D., Dong-Gyu Lee, M.D.
}

Department of Physical Medicine and Rehabilitation, College of Medicine, Yeungnam University, Daegu 705-717,

${ }^{1}$ Department of Physical Medicine and Rehabilitation, College of Medicine, Keimyung University, Daegu 700-712, Korea

\begin{abstract}
Objective To evaluate the efficacy of intradiscal methylene blue (MB) injection in patients with chronic discogenic low back pain.

Method Twenty patients with discogenic low back pain (4 males, 16 females; mean age 45.6 years) refractory to conservative management were recruited. All subjects underwent MB injection in target lumbar intervertebral discs confirmed by provocative discography. The clinical outcome was assessed by visual analog scale (VAS) and Oswestry disability index (ODI) at baseline and 1, 3, 6 and 12 months after treatment. Successful outcome was described as minimum of 2 points reduction in pain intensity compared with the baseline.

Results VAS and ODI significantly decreased after one injection. The average VAS and ODI were reduced significantly from 5.1 and 38.0 at baseline to 3.2 and 27.4 at 3 months after injection $(\mathrm{p}<0.05)$. However, the mean score of VAS at 12 month follow-up was 4.5 and we could not observe any difference between 12 months after injection and pretreatment. Eleven of twenty patients (55\%) reported successful outcomes after intradiscal MB injection at 3 month follow up and the average VAS was reduced by $3.3 \pm 1.1(p<0.05)$. At the time of 12 month follow up, pain had relapsed in 6 patients who have had satisfactory effect at 3 month follow up. Successful outcome was maintained in only 5 patients $(20 \%)$ for 1 year.

Conclusion The intradiscal MB injection is a short-term effective minimally invasive treatment indicated for discogenic back pain but it may lose its effectiveness long-term.
\end{abstract}

Key Words Intradiscal methylene blue injection, Discogenic low back pain

Received May 23, 2012; Accepted July 25, 2012

Corresponding author: Sang-Ho Ahn

Department of Physical Medicine and Rehabilitation \& Spine Center, College of Medicine, Yeungnam University, 317-1, Daemyung-dong, Nam-gu, Daegu 705-717, Korea

Tel: +82-53-620-3268, Fax: +82-53-625-3508, E-mail: spineahn@yumail. ac.kr

(c) This is an open-access article distributed under the terms of the Creative Commons Attribution Non-Commercial License (http:// creativecommons.org/licenses/by-nc/3.0) which permits unrestricted noncommercial use, distribution, and reproduction in any medium, provided the original work is properly cited.

Copyright $\odot 2012$ by Korean Academy of Rehabilitation Medicine

\section{INTRODUCTION}

Low back pain is one of the most common causes of disability. ${ }^{1-3}$ It is estimated that $80 \%$ of the population will experience back pain to a significant extent at some time during their lives. Recent studies suggested that the discogenic low back pain, which is mainly responsible for annular disruption, is one of the most common causes of chronic low back pain in $28-43 \%$ of studies. ${ }^{2,-7}$

Discogenic low back pain is non-radicular pain with- 
out spinal deformity, instability or other signs of neural tension. ${ }^{8,9}$ The pathogenesis of discogenic back pain is particularly complicated and not fully described. However, many studies suggest that discogenic low back pain caused by internal disc disruption is closely related with vascularized granulation tissue containing nociceptive nerve, extending from the outer layer of the annulus fibrosus into the nucleus pulposus. ${ }^{9,10}$ Sensitization of nociceptive nerves by various inflammatory repair mechanism may lead to chronic discogenic pain. With this assumption, it is crucial to control nerve fibers and nerve endings growing into the disc along the pathological tear. Various interventional treatments for chronic discogenic low back pain included reduction of inflammation, ablation of intradiscal nociceptors, lowering intradiscal pressure, and radiofrequency ablation of the nociceptors. ${ }^{11-19}$ However, many physicians question the efficacy of these methods despite of a clear advantage of relative minimally invasive treatment in terms of lower cost, and quicker recovery time for the affected patient. So far, from our literature review, the ideal interventional treatment of discogenic low back pain has not been established.

Methylene blue (MB) was first synthesized in 1876, and it has been used since then in many different areas of clinical medicine. ${ }^{20}$ Methylene blue, a low-molecular weight, partially liposoluable vital dye, has been proposed as a new therapeutic option to reduce surgeryinduced peritoneal adhesions. ${ }^{21,22}$ The local injection of MB has been attempted to treat various painful ailments and intractable idiopathic pruritus ani. ${ }^{23,24}$ These studies suggest intradermal methylene blue injection acts by ablation of sensory nerve endings in the skin. Sensory nerve ending ablation appears to reduce the sensation of itch transmitted by unmyelinated C-fibers, which shares a common pathway with neuropathic pain.

Recent studies revealed low dose $(0.5 \%$ or $1 \%)$ MB may prevent postoperative perineural fibrosis, which may be responsible for recurrent pain after laminectomy or discectomy. No cerebrospinal fluid leakage and no neurological deficits were seen when MB was applied to the peridural space after laminectomy site in experimental animal study. ${ }^{25}$ Intravenous MB injection given before an injection of propofol has been reported to be safe and effective in reducing the frequency and severity of pain associated with propofol injection in prospective, randomized, double blinded clinical study. ${ }^{26,27}$
Methylene blue acts as a direct inhibitor of NO synthase ${ }^{28}$ and nitric oxide has been implicated in the inflammatory processes of disc degeneration and discogenic pain. ${ }^{28-30}$ Therefore, intradiscal MB injection for discogenic pain could be suggested as a novel treatment option through inhibition of nitric oxide production. Recently, Peng suggested that MB could be applied in discogenic low back pain by its neurotropic effect, ${ }^{4,31}$ because discogenic low back pain occurred from growing of sensory nerve ending along with expansion of annular tear, and from inflammatory reaction in degenerated nucleus pulposus by a number of cytokines and NO. ${ }^{9,29,32}$ It has been attempted for treatment of discogenic low back pain in a randomized placebo-controlled trial in China, which showed astounding clinical outcome. ${ }^{4,31}$ However, replication of those results are needed from other clinical researchers prior to indication of intradiscal MB injection to be standard practice of chronic discogenic low back pain in any clinical practice situation.

Therefore, in the current study, we investigated the efficacy of the intradiscal MB injection for treatment of chronic discogenic low back pain for one year prospectively.

\section{MATERIALS AND METHODS}

\section{Subject selection}

Twenty patients (4 males, 16 females; mean age 45.6, range 26 to 63 years) among 55 Korean patients with chronic discogenic low back pain admitted to the Department of Physical Medicine and Rehabilitation for discography during the year 2010 were recruited for this study. The patients were recruited according to the following inclusion criteria ${ }^{8,9,13,23}: 1$ ) chronic discogenic low back pain of over 4 on a visual analogue scale (VAS), and over $30 \%$ on an Oswestry disability index (ODI) at baseline assessment, 2) age range 20 to 75 years, 3 ) chronic low back pain of more than 6 months in duration which was nonresponsive to conservative management, including medication and physical therapy, and the pain was provoked by prolonged sitting, 4) no neurological abnormalities in both lower extremities, 5) concordant pain provocation discography at the affected level. Exclusion criteria were the patients who have had diagnoses of: 1) severe disc degeneration ( $>50 \%$ disc height loss evidenced from plain lateral lumbar radiograph), 2) extruded or seques- 
tered herniated nucleus pulposus or spinal canal stenosis on MR imaging, 3) previous history of surgery at lumbosacral level, 4) lower extremity radicular pain, 5) spondylolisthesis or any translational instability of any lumbar segment, 6) spinal infection or tumor or other neurological disease, and 7) psychiatric disease. We evaluated subjectively all the recruited patients for schizophrenia and depression.

\section{Research procedures}

At the time of commencement of the research procedure, all the patients were once again fully informed about the procedural requirements and the manner of discography. Subjects were then instructed to assume a prone position on a fluoroscopy table and we draped the injection site using potadine for sterile conditions. Double needle technique was used for discography. The needle pathways were locally anesthetized, prior to the 22-gauge spinal needle being inserted into the annulus fibrosus, and thereafter a 25 -gauge spinal needle was placed into the center of the nucleus of each disc on the antero-posterior and lateral views under the fluoroscopic guided using a C-arm Arcadis Orbic (Siemens, Muenchen, Germany). The needle tip was then connected to the automated pressure-controlled discography APCD (Cybermedic Corp, Iksan, Korea) machine. Injection speed of contrast Bonorex ${ }^{\circledR}$ (Dae-Han Pharmaceuticals, Seoul, Korea) was set to $0.02 \mathrm{cc} / \mathrm{sec}$ in all patients and intradiscal pressure and injected volume were measured by real time.

During the discography procedure, we recorded the visual analogue scale (VAS) and check whether or not concordant pain was provoked for each patient. If the intradiscal pressure exceeded 50 psi above the static opening pressure, or the volume exceeded $3.5 \mathrm{cc}$, or VAS score exceeded 6 point, discography was terminated. Discography was performed for all the patients at L3-4, L4-5, and L5-S1 level to verify the particular disc levels in which concordant pain was provoked. In addition, L2-3 disc was also examined with spinal puncture in some patients who had reported such provoked concordant pain at all three disc levels. This is because we do not have any control disc when all three disc levels were afflicted with concordant pain.

A positive discography result was defined whenever the patient experienced exact reproduction of usual pain over VAS 6 at below 50 psi with at least one control disc.

According to Korean Good Clinical Practice requirements, all subjects provided their informed consent prior to participation in this clinical study. The research protocol and the appended informed consent document, as used for each patient, were earlier approved by the Institutional Review Board of our hospital.

Preparing the patient for intradiscal methylene blue (MB) injection

After 7 days of discography, we injected the MB $1 \mathrm{ml}$ at each level of concordant pain provoked target disc(s) and $1 \mathrm{ml}$ of $2 \%$ lidocaine hydrochloride according to the Peng's method. ${ }^{4}$ Following the procedure, all patients were instructed to avoid heavy work and strenuous exercise for 2 weeks.

\section{Outcome measurements}

For outcome measurements, we used the VAS and ODI to compare the change of pain intensity and functional disability before and after 1, 3, 6, 12 month MB treatment. All patients visited our hospital for follow-up of pain assessment after MB injection. We conducted the pain intensity interview by telephone at 12 months after treatment for the patients' convenience, following this protocol only for VAS assessment, not ODI. ODI assessments were possible only with the instrument located at our hospital.

Successful outcome after intradiscal MB injection was defined as minimum of 2 points reduction in pain intensity compared with the VAS score at pretreatment. ${ }^{33,34}$

\section{Statistical analysis}

All statistical analyses were performed using statistical package for the social sciences for windows SPSS version 18.0K (SPSS Korea, Seoul, Korea). Repeated measures of one factor analysis of variance was performed for estimated therapeutic effect after MB injection and we compared the statistical significant differences between follow-up time points. We rejected null hypotheses of no difference if $\mathrm{p}$-values were less than $\mathbf{0 . 0 5}$.

\section{RESULTS}

Twenty patients who were diagnosed with discogenic pain with provocative discography and agreed to partici- 
pate were included in this study. We checked exclusion criteria based upon clinical, radiological and psychological examinations prior to confirmation as study subjects. The participant demographic data is shown in Table 1. Total MB injection sites were 45 discs based upon the earlier provocative discography.

The average pain intensity and functional disability at pretreatment were $5.1 \pm 0.6$ (baseline VAS), 38.0 \pm 7.5 (baseline ODI). At the time of 3 months after injection, average reduction of VAS was 2.2, significantly decreased compared with pretreatment $(\mathrm{p}<0.05)$. Likewise, mean reduction of ODI was 10.2 , also significantly reduced $(\mathrm{p}<0.05)$ (Fig. 1). Eleven of twenty patients (55\%) experienced reduction of pain intensity more than 2 scores at 3 months after injection. However, VAS of 6 patients, out

Table 1. Demographic Characteristics of Study Subjects

\begin{tabular}{|lc|}
\hline \multicolumn{1}{c}{ Characteristics } & Patients $(\mathbf{n}=\mathbf{2 0})$ \\
\hline Sex & \\
Male & 4 \\
\hline Female & 16 \\
\hline Age (years) & $45.6 \pm 11.1$ \\
\hline Pain duration (months) & $85.3 \pm 97.8$ \\
\hline 6-12 months & 5 \\
\hline 12-24 months & 2 \\
\hline 24 months & 13 \\
\hline Target disc level & $2.3 \pm 0.9$ \\
\hline 1 Level & 5 \\
\hline 2 Levels & 5 \\
\hline 3 Levels & 10 \\
\hline
\end{tabular}

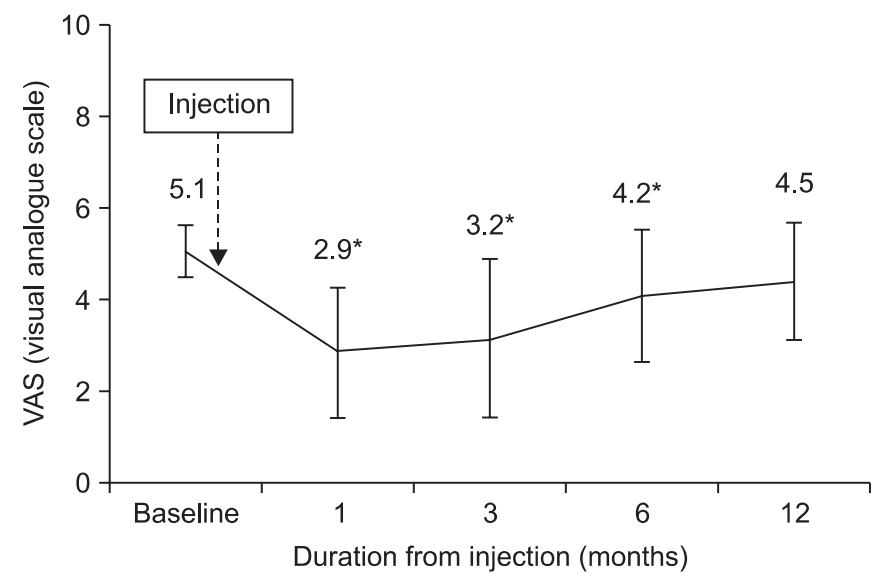

of the earlier eleven, who had a satisfactory effect at 3 month follow up, increased at 6 and 12 month follow up and successful clinical outcome of only 5 patients $(20 \%)$ was sustained at the 1 year follow up (Fig. 2). In addition, the mean score of VAS at 12 month follow-up was 4.5 and we found no significant difference between 12 months after injection and pretreatment (Fig. 1).

\section{DISCUSSION}

In this study, we tried to clarify the clinical outcome of intradiscal MB injection for the treatment of chronic

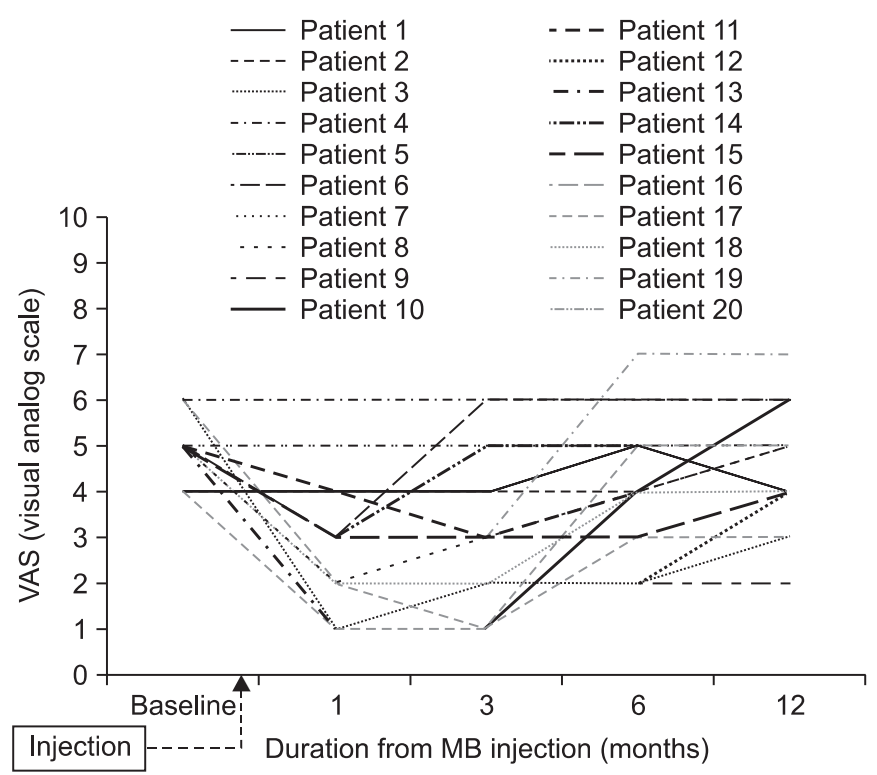

Fig. 2. Changes of the visual analog scale (VAS) after intradiscal methylene blue (MB) injection.

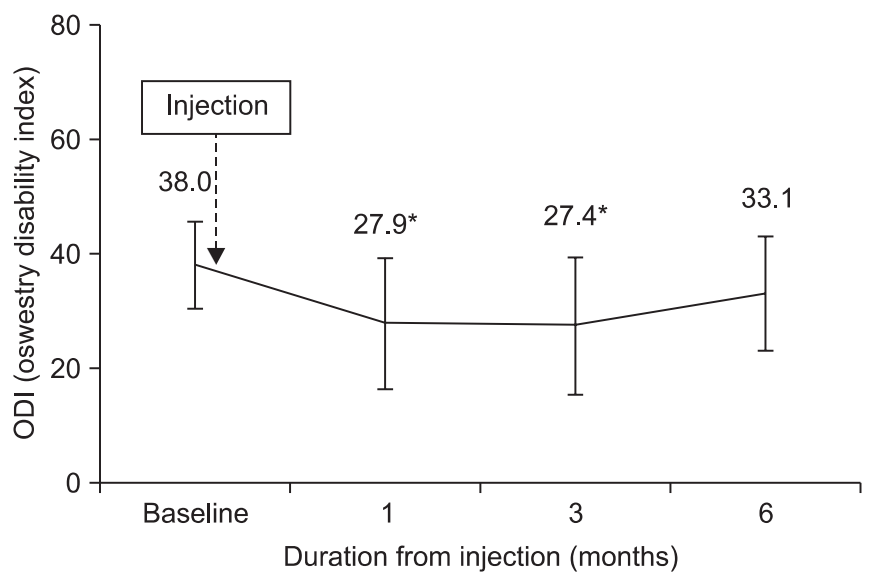

Fig. 1. Changes of the visual analog scale (VAS) and Oswestry disability index (ODI) in patients after intradiscal methylene blue (MB) injection. ${ }^{*} \mathrm{p}<0.05$. 
Table 2. Mean Scores of Visual Analog Scales (VAS) and Oswestry Disability Index (ODI) in Pre-treatment and after Intradiscal Methylene Blue (MB) Injection

\begin{tabular}{ccccc}
$\begin{array}{c}\text { Duration from MB } \\
\text { injection (months) }\end{array}$ & VAS & p & ODI & p \\
\hline Baseline & $5.1(0.6)$ & \multicolumn{2}{c}{$38.0(7.5)$} \\
\hline 1 & $2.9(1.4)$ & $0.000^{*}$ & $27.9(11.4)$ & $0.000^{*}$ \\
3 & $3.2(1.7)$ & $0.000^{*}$ & $27.4(12.0)$ & $0.001^{*}$ \\
6 & $4.2(1.4)$ & $0.016^{*}$ & $33.1(10.0)$ & 0.067 \\
12 & $4.5(1.3)$ & 0.055 & \\
\hline
\end{tabular}

Values are mean (SD)

p: Values of the effect of MB injection comparing data of baseline using repeated measured one factor analysis ${ }^{*} \mathrm{p}<0.05$

discogenic low back pain. Follow-up mean VAS and ODI significantly decreased after injection at one and three months, respectively. In our opinion, VAS data showed intradiscal MB injection was effective for up to 6 months, and ODI data for 3 months (Table 2). However, the mean scores of VAS at baseline and 12 month follow-up were not different, indicating $\mathrm{MB}$ injection to be ineffective in the longer 12 month duration. Intradiscal MB injection was successful in 11 patients (55\%) at 3 month follow up. However, at the time of 12 month follow up, pain relapsed in 6 patients, who had a satisfactory effect at 3 month follow up, so the satisfactory effect was maintained in only 5 patients (20\%) for 1 year in duration.

Intradiscal steroid injection was introduced to give clinical improvement by decreasing intradiscal inflammation in patients with chronic discogenic low back pain and it was considered successful in approximately $25 \%$ at 1 year follow-up, ${ }^{35}$ However, a randomized controlled study did not show long-term clinical benefit of intradiscal steroid injection in patients with similar chronic low back pain. ${ }^{36}$

Therefore, there has been increasing interest in the development of physiologic treatment options that modify nociceptors in chronic discogenic pain. For chemoneuromodulation of intradiscal nociceptive fibers, intradiscal hypertonic dextrose and methylene blue were introduced.

A study of intradiscal hypertonic dextrose injection for chronic discogenic low back pain found that $43.4 \%$ of patients showed a sustained treatment response for a minimum of six months. ${ }^{37}$ The outcome of hypertonic dextrose injection is not so different with that of our intradiscal MB injection. It should be investigated in the fu- ture, as to which one is better for the chronic discogenic low back pain considering safety and efficacy.

The methylene blue was introduced for new and innovative method for treatment for discogenic pain, the effect of MB enables it to destroy nerve endings or ingrown nociceptors, but not nerves and alleviates the chronic inflammatory response that can lead to fibrosis. ${ }^{4,31}$ In 2007, Peng introduced intradiscal MB injection in 24 patients with refractory chronic discogenic low back pain poorly responded to conservative treatment. ${ }^{31}$ Recently, Peng also demonstrated the efficacy and safety of intradiscal $M B$ injection in 72 patients with discogenic low back pain by randomized placebo-controlled trial. ${ }^{4}$ The outcome of this study was so effective that the intradiscal MB injection group showed 52.5 reduction in mean numeric rating score and $91.6 \%$ in satisfaction rate at 24 months after procedure. Therefore, they insisted that intradiscal MB injection may be an effective treatment for chronic intractable discogenic pain which had earlier required surgery. These striking results could lead to use of intradiscal MB for discogenic low back pain as the preferable treatment. However, a single study is not sufficient to provide the evidence-based approach as standard treatment for chronic discogenic low back pain, and replication is necessary for new technique to replace standard practice. Our study showed that the efficacy of intradiscal MB injection was maintained only in $20 \%$ patients after 12 months. This poor 12 month outcome could not support that MB injection is an effective treatment method for discogenic low back pain. The difference of outcome between our present study and Peng's study might be quite significant. Generally, outcomes of a randomized placebo-controlled trial are worse than observational study, because the effect of natural improvement is removed, and assessors and subjects are blind to given treatment. In this case, reversed results were shown. We do not know if Chinese subjects report more favorably to their assessors than Korean subjects.

We think that reduced pain (55\%) in the present study at three months after treatment means repeated intradiscal MB injection at regular intervals could be helpful for chronic discogenic pain. Further studies about whether repeated MB injections work for chronic discogenic pain might be of value. However, it is not established whether MB has cellular toxicity to nucleus pulposus cells. Therefore, potential risk to aggravate disc degeneration in injected disc should be excluded to guarantee long-term 
safety of intradiscal MB injection.

MB has potent neurotoxic effects when administered intrathecally or epidurally with large doses, ${ }^{38-40}$ although recent novel research showed low doses $(0.5 \%, 1 \%$ and $2 \%$ ) of MB may be an effective in preventing perineural fibrosis after lumbar laminectomy, and no cerebrospinal fluid leakage or neurologic deficits were seen. ${ }^{28}$ Intravenous $50 \mathrm{mg} \mathrm{MB}$ injection is effective in reducing pain during propofol injection. ${ }^{30}$ However, spinal interventionists should take care to avoid intrathecal MB injection during intradiscal injection, although it could not happened in normal clinical situation. In addition, repeated large doses leaking into the epidural space from ruptured disc should be avoided because there was a report that repeated large doses MB injection into epidural space in cats caused neurological impairment. ${ }^{38}$

Among its limitations, this study does not include a non-intervention control group. The observed satisfactory response in this study could reflect natural history. However, to lessen the possibility of natural improvement without MB injection in present study, subjects were chosen who had chronic discogenic pain over symptom duration of 6 months from onset of pain refractory to conservative treatment. It is thought that the natural course of chronic pain of participants included in this study had already reached plateau status. Although this study was conducted without a control group, the result of this study might provide relatively pure outcome of intradiscal MB injection. Another limitation of our study is the small number of patients. We believe that further studies about whether repeated MB injections might be effective for chronic discogenic pain with a larger sample size should be undertaken to address this hypothesis.

\section{CONCLUSION}

In conclusion, in the current study, we examined the efficacy of intradiscal MB injection in patients with chronic discogenic low back pain for one year prospectively. Follow-up mean VAS and ODI significantly decreased after injection between the time of one and three months. We found that a successful effect was acquired in $55 \%$ three months after treatment and the effect was maintained for 12 months in only $20 \%$ of patients. The intradiscal MB injection therapy might be effective for chronic discogenic low back pain for short term, but not for long-term. Further studies about whether repeated MB injections work for chronic discogenic pain might be necessary.

\section{ACKNOWLEDGEMENTS}

This study was supported by a grant of the Korea Health care technology R\&D Project, Ministry for Health, Welfare \& Family Affairs, Republic of Korea (A084177).

\section{REFERENCES}

1. Andersson GB. Epidemiologic features of chronic low back pain. Lancet 1999; 354: 581-585

2. Schwarzer AC, Aprill CN, Derby R, Fortin J, Kine G, Bogduk N. The prevalence and clinical features of internal disc disruption in patients with chronic low back pain. Spine 1995; 20: 1878-1883

3. Andersson GB. Epidemiology of low back pain. Acta Orthop Scand Suppl 1998; 281: 28-31

4. Peng B, Pang X, Wu Y, Zhao C, Song X. A randomized placebo-controlled trial of intradiscal methylene blue injection for the treatment of chronic discogenic low back pain. Pain 2010; 149: 124-129

5. Ito M, Incorvaia KM, Yu SF, Fredrickson BE, Yuan HA, Rosenbaum AE. Predictive signs of discogenic lumbar pain on magnetic resonance imaging with discography correlation. Spine 1998; 23: 1252-1260

6. Zhou YL, Abdi S. Diagnosis and minimally invasive treatment of lumbar discogenic pain - a review of the literature. Clin J Pain 2006; 22: 468-481

7. Saal JA. Natural history and nonoperative treatment of lumbar disc herniation. Spine 1996; 21: 2S-9S

8. Smith SE, Darden BV, Rhyne AL, Wood KE. Outcome of unoperated discogram positive low back pain. Spine 1995; 20: 1997-2001

9. Peng B, Wu W, Hou S, Li P, Zhang C, Yang Y. The pathogenesis of discogenic low back pain. J Bone Joint Surg Br 2005; 87: 62-67

10. Moneta GB, Videman T, Kaivanto K, Aprill C, Spivey M, Vanharanta H, Sachs BL, Guyer RD, Hochschuler $\mathrm{SH}$, Raschbaum RF, et al. Reported pain during lumbar discography as a function of annular ruptures and disc degeneration. A re-analysis of 833 discograms. Spine 1994; 19: 1968-1974

11. Kallewaard JW, Terheggen MA, Groen GJ, Sluijter ME, Derby R, Kapural L, Mekhail N, van Kleef M. Discogenic low back pain. Pain Pract 2010; 10: 560-579

12. Pauza KJ, Howell S, Dreyfuss P, Peloza JH, Dawson K, 
Boqduk N. A randomized, placebo-controlled trial of intradiscal electrothermal therapy for the treatment of discogenic low back pain. Spine J 2004; 4: 27-35

13. Singh K, Ledet E, Carl A. Intradiscal therapy: a review of current treatment modalities. Spine 2005; 30: S20S26

14. Rohof O. Intradiscal pulsed radiofrequency application following provocative discography for the management of degenerative disc disease and concordant pain: a pilot study. Pain Pract 2012; 12: 342-349

15. Freeman BJ, Fraser RD, Cain CM, Hall DJ, Chapple DC. A randomized, double-blind, controlled trial: intradiscal electrothermal therapy versus placebo for the treatment of chronic discogenic low back pain. Spine 2005; 30: 2369-2378

16. Finch PM, Price LM, Drummond PD. Radiofrequency heating of painful annular disruptions: one-year outcomes. J Spinal Disord Tech 2005; 18: 6-13

17. McMillan MR, Patterson PA, Parker V. Percutaneous laser disc decompression for the treatment of discogenic lumbar pain and sciatica: a preliminary report with 3-month follow-up in a general pain clinic population. Photomed Laser Surg 2004; 22: 434-438

18. Skliarenko ET, Tarabanova LV, Pashkov EP. Cryotherapy of pain syndromes associated with degenerativedystrophic diseases of the spine. Ortop Travmatol Protez 1986; 10: 28-31

19. Lee SH, Derby R, Sul D, Hong J, Kim GH, Kang S, Kim $\mathrm{NH}$, Yoo SH, Lee SJ, Hong YK, et al. Efficacy of a new navigable percutaneous disc decompression device (L'DISQ) in patients with herniated nucleus pulposus related to radicular pain. Pain Med 2011; 12: 370-376

20. Wainwright M, Crossley KB. Methylene blue - a therapeutic dye for all seasons? J Chemother 2002; 14: 431443

21. Cetin M, Duran B, Demirkoprulu N, Guvenal T, Erden $\mathrm{O}$, Cetin A. Effects of diazeniumdiolates (NONOates) and methylene blue on the reduction of postoperative adhesion in rats. Gynecol Obstet Invest 2004; 57: 186190

22. Heydrick SJ, Reed KL, Cohen PA, Aarons CB, Gower AC, Becker JM, Stucchi AF. Intraperitoneal administration of methylene blue attenuates oxidative stress, increases peritoneal fibrinolysis, and inhibits intraabdominal adhesion formation. J Surg Res 2007; 143: 311-319

23. Farouk R, Lee PW. Intradermal methylene blue injec- tion for the treatment of intractable idiopathic pruritus ani. Br J Surg 1997; 84: 670

24. Mentes BB, Akin M, Leventoglu S, Gultekin FA, Oguz $M$. Intradermal methylene blue injection for the treatment of intractable idiopathic pruritus ani: results of 30 cases. Tech Coloproctol 2004; 8: 11-14

25. Farrokhi MR, Vasei M, Fareghbal S, Farrokhi N. The effect of methylene blue on peridural fibrosis formation after laminectomy in rats: an experimental novel study. Spine J 2011; 11: 147-152

26. National Toxicology Program. Toxicology and carcinogenesis studies of methylene blue trihydrate (Cas No. 7220-79-3) in F344/N rats and B6C3F1 mice (gavage studies). Natl Toxicol Program Tech Rep Ser 2008; 540: 1-224

27. Salman AE, Salman MA, Saricaoglu F, Akinci SB, Aypar Ü. Pain on injection of propofol: a comparison of methylene blue and lidocaine. J Clin Anesth 2011; 23: 270-274

28. Mayer B, Brunner F, Schmidt K. Inhibition of nitric oxide synthesis by methylene blue. Biochem Pharmacol 1993; 45: 367-374

29. Poveda L, Hottiger M, Boos N, Wuertz K. Peroxynitrite induces gene expression in intervertebral disc cells. Spine 2009; 34: 1127-1133

30. Liu GZ, Ishihara H, Osada R, Kimura T, Tsuji H. Nitric oxide mediates the change of proteoglycan synthesis in the human lumbar intervertebral disc in response to hydrostatic pressure. Spine 2001; 26: 134-141

31. Peng B, Zhang Y, Hou S, Wu W, Fu X. Intradiscal methylene blue injection for the treatment of chronic discogenic low back pain. Eur Spine J 2007; 16: 33-38

32. Kang JD, Stefanovic-Racic M, McIntyre LA, Georgescu $\mathrm{HI}$, Evans $\mathrm{CH}$. Toward a biochemical understanding of human intervertebral disc degeneration and herniation. Contributions of nitric oxide, interleukins, prostaglandin E2, and matrix metalloproteinases. Spine 1997; 22: 1065-1073

33. Farrar JT, Portenoy RK, Berlin JA, Kinman JL, Strom BL. Defining the clinically important difference in pain outcome measures. Pain 2000; 88: 287-294

34. Hägg O, Fritzell P, Nordwall A. The clinical importance of changes in outcome scores after treatment for chronic low back pain. Eur Spine J 2003; 12: 12-20

35. Buttermann GR. The effect of spinal steroid injections for degenerative disc disease. Spine J 2004; 4: 495-505

36. Khot A, Bowditch M, Powell J, Sharp D. The use of in- 
tradiscal steroid therapy for lumbar spinal discogenic pain: a randomized controlled trial. Spine 2004; 29: 833-837

37. Miller MR, Mathews RS, Reeves KD. Treatment of painful advanced internal lumbar disc derangement with intradiscal injection of hypertonic dextrose. Pain Physician 2006; 9: 115-121

38. Poppers PJ, Mastri AR, Lebeaux M, Covino BG. The ef- fect of methylene blue on neural tissue. Anesthesiology 1970; 33: 335-340

39. Gross SW. Letter: neurological deficits resulting from intrathecal administration of methylene blue. Neuroradiology 1974; 7: 117

40. Sharr MM, Weller RO, Brice JG. Spinal cord necrosis after intrathecal injection of methylene blue. J Neurol Neurosurg Psychiatry 1978; 41: 384-386 